\title{
Direct Electrocortical Stimulation
}

National Cancer Institute

\section{Source}

National Cancer Institute. Direct Electrocortical Stimulation. NCI Thesaurus. Code

C116562.

A method for functional brain mapping that applies electrical stimulation to the exposed cortex of a patient and marks the cortex according to patient response. 